\section{Delayed Neurovascular Dysfunction Is Alleviated by Hydrogen in Asphyxiated Newborn Pigs}

\author{
Orsolya Oláh ${ }^{a}$ Valéria Tóth-Szüki ${ }^{a}$ Péter Temesváric Ferenc Bari ${ }^{\mathrm{b}}$ \\ Ferenc Domokia
}

Departments of a Physiology and ${ }^{b}$ Medical Physics and Informatics, Faculty of Medicine, University of Szeged, Szeged, and ' Department of Pediatrics, University Teaching Hospital Orosháza, Orosháza, Hungary

C) Free Author
Copy - for per-
sOnal use only
ANY DISTRIBUTION OF THIS
ARTICLE WITHOUT WRITTEN
CONSENT FROM S. KARGER
AG, BASEL IS A VIOLATION
OF THE COPYRIGHT.
Written permission to distrib-
ute the PDF will be granted
against payment of a per-
mission fee, which is based
on the number of accesses
required. Please contact
permission@ karger.ch

\section{Key Words}

Hypoxic-ischemic encephalopathy · Neuroprotection · Pial arteriole $\cdot$ Cerebrovascular regulation $\cdot$ Cranial window

\begin{abstract}
Background: The neurovascular unit encompasses the functional interactions of cerebrovascular and brain parenchymal cells necessary for the metabolic homeostasis of neurons. Previous studies indicated marked but only transient (1-4 h) reactive oxygen species-dependent neurovascular dysfunction in newborn pigs after severe hypoxic/ischemic $(\mathrm{H} / \mathrm{l})$ stress contributing to the neuronal injury after birth asphyxia. Objectives: Our major purpose was to determine if neurovascular dysfunction would also occur later, at $24 \mathrm{~h}$ after a milder $\mathrm{H} / \mathrm{I}$ stress. We also tested if the putative hydroxyl radical scavenger hydrogen $\left(\mathrm{H}_{2}\right)$ exerted neurovascular protection. Methods: Anesthetized, ventilated piglets were assigned to three groups of 9 animals: time control, asphyx$\mathrm{ia} /$ reventilation with air, and asphyxia/reventilation with air $+2.1 \% \mathrm{H}_{2}$ for $4 \mathrm{~h}$. Asphyxia was induced by suspending ventilation for $8 \mathrm{~min}$. Cerebrovascular reactivity (CR) of pial arterioles was determined using closed cranial window/intravital microscopy $24 \mathrm{~h}$ after asphyxia to the endothelium-dependent cerebrovascular stimulus hypercapnia, the neuronal function-dependentstimulus $\mathrm{N}$-methyl-D-aspartate (NMDA),
\end{abstract}

norepinephrine, and sodium nitroprusside. The brains were subjected to histopathology. Results: Hemodynamic parameters, blood gases, and core temperature did not differ significantly among the experimental groups. In the early reventilation period, the recovery of electroencephalographic activity was significantly better in $\mathrm{H}_{2}$-treated animals. Asphyxia/reventilation severely attenuated $C R$ to hypercapnia and NMDA; however, reactivity to norepinephrine and sodium nitroprusside were unaltered. $\mathrm{H}_{2}$ fully or partially preserved CR to hypercapnia or NMDA, respectively. Histopathology revealed modest neuroprotection afforded by $\mathrm{H}_{2}$. Conclusions: Severe stimulus-selective delayed neurovascular dysfunction develops and persists even after mild $\mathrm{H} / \mathrm{I}$ stress. $\mathrm{H}_{2}$ alleviates this delayed neurovascular dysfunction that can contribute to its neuroprotective effect.

Copyright $\odot 2013$ S. Karger AG, Basel

\section{Introduction}

Perinatal asphyxia elicits severe brain injury playing a significant role in perinatal mortality or leading to hypoxicischemic encephalopathy (HIE) in the survivors. Although moderate whole-body hypothermia provides considerable neuroprotection [1], there are also potential dangers of this treatment [2]; thus, further studies on the pathomecha-

\section{KARGER}

E-Mail karger@karger.com

www.karger.com/neo
(C) 2013 S. Karger AG, Basel

1661-7800/13/1042-0079\$38.00/0
Orsolya Oláh, MD

Department of Physiology

Faculty of Medicine, University of Szeged

Dóm tér 10, HU-6720 Szeged (Hungary)

E-Mail olah.orsolya@med.u-szeged.hu 
nisms of HIE are warranted in order to develop new therapeutic neuroprotective strategies to further alleviate neuronal damage and to improve clinical outcome.

The contribution of neurovascular unit dysfunction to the development of HIE so far has received little attention, although its role in neuronal injury has been recently widely recognized in adult stroke [3]. The term neurovascular unit describes the morphological and functional interactions of neurons, astrocytes, and various cerebromicrovascular cells collectively responsible for the local metabolic homeostasis of neurons. We and others have repeatedly shown that hypoxic/ischemic (H/I) stress in newborn piglets severely attenuated cerebrovascular reactivity (CR) to various so-called 'hypoxia-ischemia-sensitive' stimuli determined in pial arterioles $1 \mathrm{~h}$ after the insult indicating severe acute neurovascular unit dysfunction [4-7]. The attenuated CR showed spontaneous recovery appearing intact as early as $4 \mathrm{~h}$ after the $\mathrm{H} / \mathrm{I}$ insult $[5,6]$. These findings suggested that neurovascular unit dysfunction might play a role in neuronal damage only in the acute reoxygenation phase. However, the neuronal damage further progresses in the subacute phase coinciding with the appearance of the so-called secondary energy failure often developing $\sim 24 \mathrm{~h}$ after the $\mathrm{H} / \mathrm{I}$ stress [8], and chronic hypoxia is known also to elicit long-term alterations in the responses of piglet cerebral arteries [9]. Nevertheless, CR has been virtually uncharted during this period in newborn models of HIE.

Reactive oxygen species (ROS) produced in the early reoxygenation period have been shown to be responsible for acute neurovascular unit dysfunction [10]. Accordingly, various antioxidant approaches have been shown to prevent the acute attenuation of CR in the piglet. Recently, molecular hydrogen $\left(\mathrm{H}_{2}\right)$ - a putative selective inhibitor of hydroxyl radicals [11] - was found to prevent acute post-asphyxic CR impairment with a concomitant neuroprotective effect in piglets [12].

The main hypotheses of the present study were to investigate if (1) significant neurovascular dysfunction develops $24 \mathrm{~h}$ after $\mathrm{H} / \mathrm{I}$ stress in newborn piglets, and if (2) $\mathrm{H}_{2}$ could alleviate neurovascular dysfunction also in this time period.

\section{Materials and Methods}

\section{Materials}

Drug sources were Na-thiopental (Sandoz, Kundl, Austria), morphine hydrochloride, penicillin (Teva, Petah Tikva, Israel), midazolam (Torrex Pharma, Vienna, Austria), gentamicin, norepinephrine (NE; Sanofi, Paris, France), a-chloralose, N-methyl-D-aspartate (NMDA), and sodium nitroprusside (SNP; Sigma-
Aldrich, St. Louis, Mo., USA). All gas mixtures used for ventilation were obtained from the Messer Group GmbH, Bad Soden, Germany.

\section{Animals}

Newborn (1-2 days old, body weight $1.5-2.5 \mathrm{~kg}$ ) male LargeWhite piglets $(\mathrm{n}=27)$ were obtained from a local company (Pigmark Ltd Co., Szeged, Hungary). All procedures were approved by the Animal Care and Use Committee of the University of Szeged.

Anesthesia was induced with Na-thiopental $(45 \mathrm{mg} / \mathrm{kg}$, i.p.) followed by intubation through tracheotomy and artificial ventilation with medical air $\left(21 \% \mathrm{O}_{2}\right.$, balance $\left.\mathrm{N}_{2}\right)$, using a pressure-controlled ventilator. The inspired gas was warmed and humidified, the ventilation rate $(25-35 / \mathrm{min})$ and the peak inspiratory pressure (100-125 $\mathrm{mm} \mathrm{H}_{2} \mathrm{O}$ ) were set to keep blood gases and oxygen saturation in the physiological range. The right femoral and jugular veins were catheterized to monitor $\mathrm{pH}, \mathrm{pCO}_{2}$, glucose, and to infuse anesthetic drugs (morphine, $100 \mu \mathrm{g} / \mathrm{kg}$ bolus, $10 \mu \mathrm{g} / \mathrm{kg} / \mathrm{h}$; midazolam, $250 \mu \mathrm{g} / \mathrm{kg}$ bolus, $250 \mu \mathrm{g} / \mathrm{kg} / \mathrm{h}$ ), fluids ( $5 \%$ glucose, $0.45 \% \mathrm{NaCl}, 2-5 \mathrm{ml} / \mathrm{kg} / \mathrm{h}$ ), and antibiotics (penicillin $50 \mathrm{mg} / \mathrm{kg}$ / $12 \mathrm{~h}$; gentamicin $2.5 \mathrm{mg} / \mathrm{kg} / 12 \mathrm{~h}$ ), respectively.

The instrumented animals were placed in a prone position into an ICU newborn resuscitation crib (SPC 78-1; Narco Air-Shields, Inc., Hatboro, Pa., USA) allowing servo-controlled temperature regulation. Oxygen saturation, heart rate, ECG, arterial blood pressure, and body temperature were monitored with a Hewlett-Packard M1094 monitor (Palo Alto, Calif., USA); the data were recorded online using a PC (MecifView, Arlington, Mass., USA). Amplitude-integrated electroencephalography (aEEG) was performed with two parietal needle electrodes coupled to an EEG amplifier (Experimetria Ltd, Balatonfüred, Hungary), the raw EEG data were converted to aEEG recording and stored on a PC using a custom software according to the specifications described previously [13].

Figure 1 shows the flowchart of the experiments. Piglets were divided into three experimental groups of 9 animals: (1) time control animals (group 1), (2) asphyxiated controls reventilated with air (group 2), and (3) asphyxiated animals reventilated for $4 \mathrm{~h}$ with $\mathrm{H}_{2}$-supplemented air $\left(2.1 \% \mathrm{H}_{2}, 21 \% \mathrm{O}_{2}\right.$, balance $\mathrm{N}_{2}$, group 3$)$.

$22 \mathrm{~h}$ after asphyxia, the anesthesia was switched to $\alpha$-chloralose (30 mg/kg bolus, 3-5 mg/kg/h). The femoral artery was catheterized to measure arterial blood pressure and blood gases. The head was fixed in a stereotactic frame and a closed cranial window was inserted over the left parietal cortex. The closed cranial window was filled with artificial cerebrospinal fluid (aCSF), and CR was determined with intravital videomicroscopy as described previously $[12,14]$.

\section{Histopathology}

The common carotid arteries were catheterized in the anesthetized animals and the brain was perfused with $4^{\circ} \mathrm{C}$ saline. The left hemisphere of the removed brain was then immersion-fixed in $4{ }^{\circ} \mathrm{C} 4 \%$ paraformaldehyde within 5-6 min. Tissue samples were dissected from different brain areas (fig. 1), paraffin-embedded and $4-\mu \mathrm{m}$ sections were stained with hematoxylin and eosin. The neurons were morphologically identified (large soma, large round euchromatic nucleus and single prominent nucleolus). For each tissue sample, neuronal damage was expressed as the percentage of shrunken hyperchromatic 'red' neurons with pyknotic nuclei compared with the total number of neurons counted in $10 \times 10$ fields of view at $20 \times$ magnification by an examiner blinded to the experimental groups as described previously [12]. 


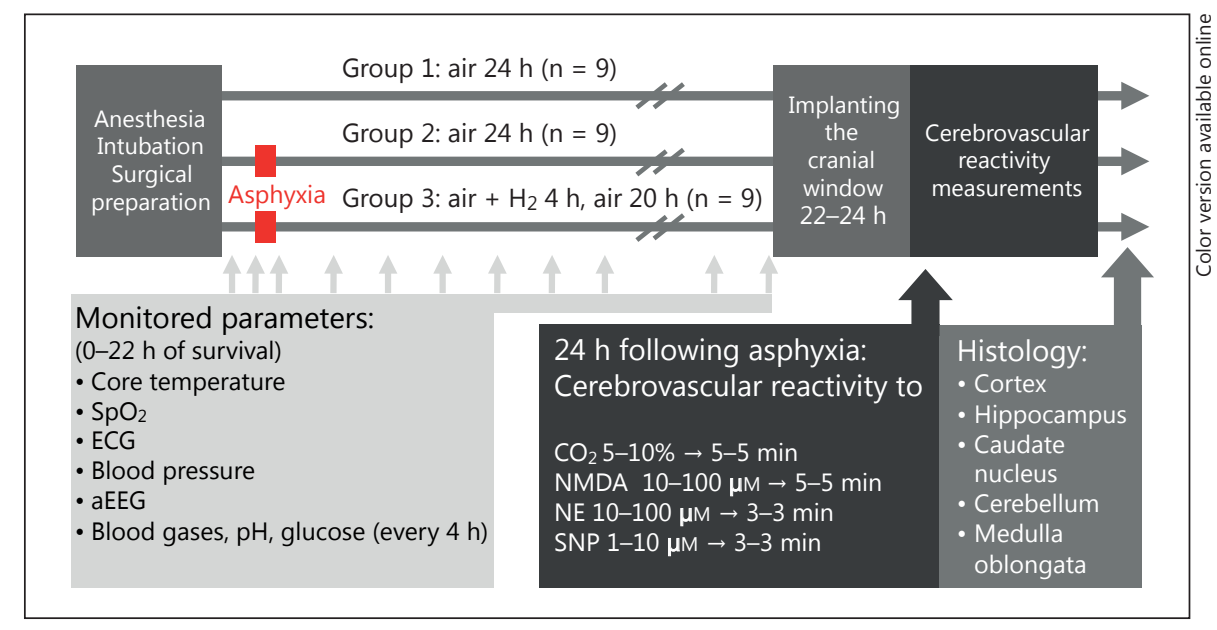

Fig. 1. Study design: asphyxia was induced with clamping the endotracheal tube and suspending the ventilation for $8 \mathrm{~min}$. After asphyxia, reventilation was started according to the experimental group. There was no need for cardiac resuscitation at this level of $\mathrm{H} / \mathrm{I}$ stress [24]. $4 \mathrm{~h}$ following asphyxia the ventilation was continued with air in every group. In this period, $\mathrm{FiO}_{2}$ was increased in some animals from $21 \%$ up to $25 \%$ to maintain satisfactory oxygenation. Vital parameters and aEEG were continuously monitored, and recorded for $10 \mathrm{~min}$ before the asphyxiation, during the asphyxia, for the first $10 \mathrm{~min}$ of reventilation and then 1-10 min from the 1 st to the 22 nd hours of reventilation each hour. Venous $\mathrm{pH}$, blood gases, and blood glucose level were checked before the asphyxia, in the 7th minute of asphyxia and in every 4th hour of

\section{Statistical Analysis}

Parametric data are expressed as mean \pm SEM. Data were analyzed with a statistical software (SigmaPlot 11; Systat Software, Inc., San Jose, Calif., USA). CR and physiological parameters were analyzed with two-way repeated measures ANOVA, the morphometric data with one-way ANOVA. Student-Newman-Keuls post hoc test was used for pairwise comparisons. The aEEG scores of groups 2 and 3 were compared with the Mann-Whitney U test. p values $<0.05$ were considered statistically significant.

\section{Results}

\section{Physiological Parameters}

In group 1 , the monitored physiological parameters were stable and within the physiological range (fig. 2a), furthermore the aEEG showed continuous activity throughout the 22-hour observation period. In groups 2-3, asphyxia elicited an isoelectric aEEG within $1 \mathrm{~min}$. Severe hypercapnia, acidosis (fig. 2b), hypoxia and bradycardia $(<65 \mathrm{bpm})$ developed by the 8 th minute. Upon reventilation, the physiological parameters gradually recovered in 2-3 h (fig. 2a), and then they were not different reventilation period. CR was determined sequentially to graded hypercapnia, NMDA (10-100 $\mu \mathrm{M}), \mathrm{NE}(10-100 \mu \mathrm{M})$, and SNP (1$10 \mu \mathrm{M}) 24 \mathrm{~h}$ after the asphyxia. Graded hypercapnia was evoked by ventilating with gas mixtures containing $5-10 \% \mathrm{CO}_{2}\left(21 \% \mathrm{O}_{2}\right.$, balance $\mathrm{N}_{2}$ ) for 5-6 min each. Ventilation was then switched back to room air, and pial arteriolar dilation was allowed to return to the baseline level. After stabilization, the cranial window was rinsed with aCSF. The drugs were then locally applied to the cerebral cortex by gently flushing the cranial window with aCSF containing increasing drug concentrations 3-5 min for each concentration. Between different stimuli the cerebral cortex was repeatedly washed with aCSF until baseline pial arteriolar dilation was restored.

from the time controls. The originally isoelectric aEEG gradually recovered to continuous activity over the observation period. Recovery was significantly faster during the $\mathrm{H}_{2}$ ventilation period in group 3 (fig. 3b).

\section{Assessment of CR}

$5-10 \% \mathrm{CO}_{2}$ ventilation resulted in similar increases in arterial $\mathrm{pCO}_{2}$ with simultaneous $\mathrm{pH}$ decreases in all experimental groups (table 1). Graded hypercapnia elicited dose-dependent pial arteriolar dilation in group 1 (fig. 4a). In contrast, hypercapnia-induced vasodilation was severely attenuated $24 \mathrm{~h}$ after asphyxia in group 2 but was essentially unaltered in the animals reventilated with $\mathrm{H}_{2}$ (group 3; fig. 4a). NMDA also induced dose-dependent vasodilation in group 1 , which was virtually abolished in group 2 and significantly attenuated in group 3. Notably, $\mathrm{CR}$ to NMDA was significantly higher in the $\mathrm{H}_{2}$-ventilated animals (fig. 4b). The pial arteriolar constriction to NE or the dilation to SNP was not significantly affected by asphyxia (fig. 4c, d); interestingly, vasoconstriction to NE was significantly smaller in the $\mathrm{H}_{2}$-ventilated group 3 as compared with time controls. 

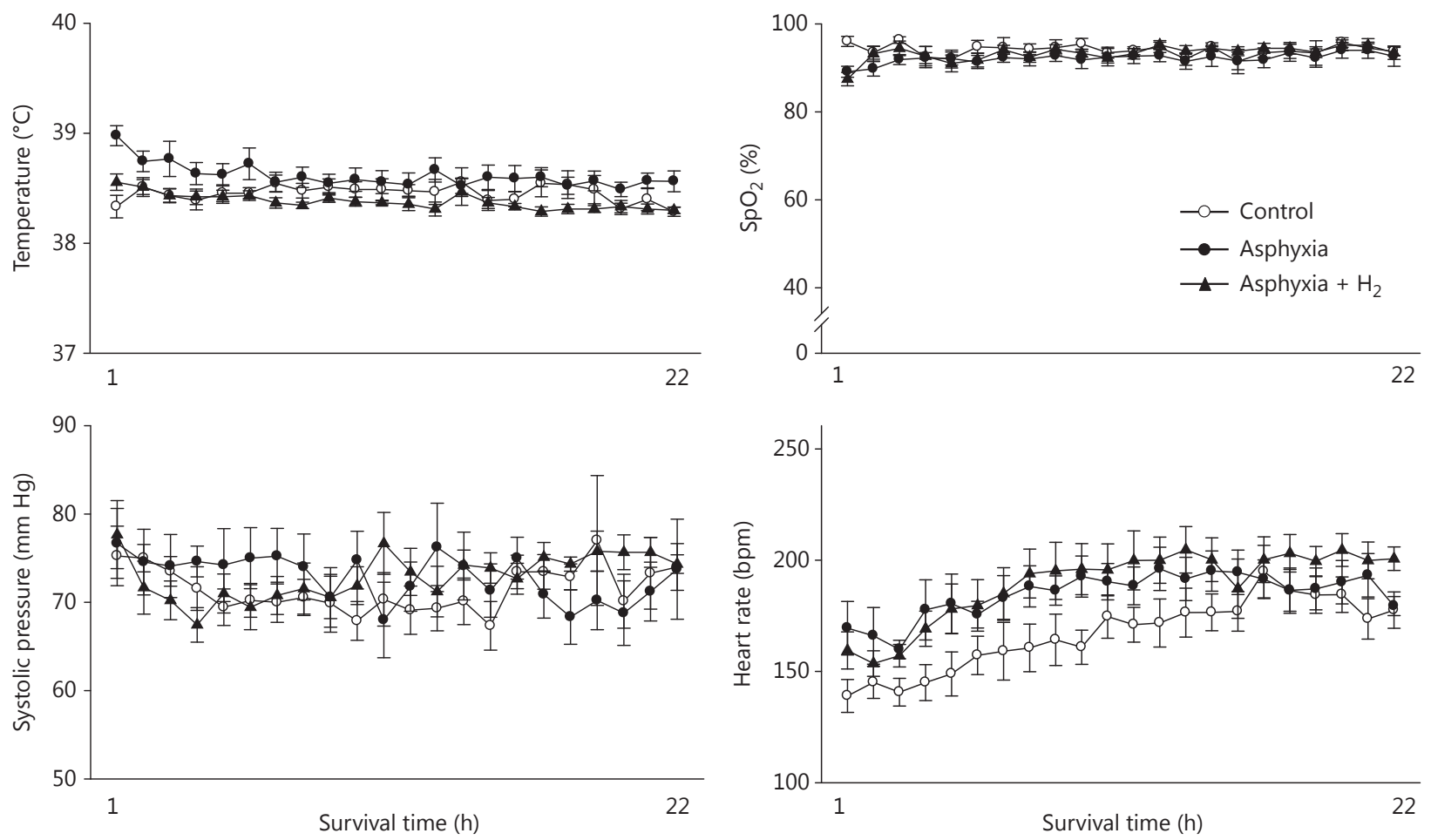

\begin{tabular}{|c|c|c|c|c|c|c|c|c|c|}
\hline & \multicolumn{3}{|c|}{ Control } & \multicolumn{3}{|c|}{ Asphyxia } & \multicolumn{3}{|c|}{ Asphyxia $+\mathrm{H}_{2}$} \\
\hline & $\mathrm{pH}$ & $\mathrm{pCO}_{2}$ & Glucose & $\mathrm{pH}$ & $\mathrm{pCO}_{2}$ & Glucose & $\mathrm{pH}$ & $\mathrm{pCO}_{2}$ & Glucose \\
\hline Baseline & $7.43 \pm 0.07$ & $36 \pm 4$ & $3.5 \pm 0.6$ & $7.39 \pm 0.02$ & $39 \pm 2$ & $5.6 \pm 0.9$ & $7.39 \pm 0.02$ & $36 \pm 3$ & $5.9 \pm 1.9$ \\
\hline Asphyxia & & & & $6.94 \pm 0.04 *$ & $89 \pm 11 *$ & & $6.98 \pm 0.02 *$ & $94 \pm 5 *$ & \\
\hline $4 \mathrm{~h}$ & $7.38 \pm 0.02$ & $43 \pm 3$ & $4.0 \pm 0.8$ & $7.36 \pm 0.03$ & $45 \pm 3$ & $4.3 \pm 0.5$ & $7.37 \pm 0.03$ & $42 \pm 5$ & $3.7 \pm 0.5$ \\
\hline $8 \mathrm{~h}$ & $7.32 \pm 0.02$ & $47 \pm 6$ & $3.3 \pm 0.6$ & $7.34 \pm 0.04$ & $43 \pm 3$ & $4.5 \pm 0.9$ & $7.34 \pm 0.03$ & $48 \pm 3$ & $4.5 \pm 1.0$ \\
\hline $12 \mathrm{~h}$ & $7.33 \pm 0.03$ & $49 \pm 6$ & $4.3 \pm 1.1$ & $7.33 \pm 0.03$ & $45 \pm 5$ & $4.0 \pm 0.5$ & $7.33 \pm 0.03$ & $45 \pm 5$ & $3.9 \pm 0.9$ \\
\hline $16 \mathrm{~h}$ & $7.30 \pm 0.06$ & $48 \pm 6$ & $3.2 \pm 0.5$ & $7.32 \pm 0.03$ & $49 \pm 5$ & $4.9 \pm 0.9$ & $7.36 \pm 0.03$ & $50 \pm 4$ & $3.1 \pm 0.3$ \\
\hline $20 \mathrm{~h}$ & $7.39 \pm 0.05$ & $38 \pm 4$ & $4.3 \pm 0.7$ & $7.35 \pm 0.04$ & $47 \pm 6$ & $2.8 \pm 0.1$ & $7.32 \pm 0.03$ & $53 \pm 6$ & $3.1 \pm 0.2$ \\
\hline
\end{tabular}

Fig. 2. a Rectal temperature and hemodynamic parameters in the three experimental groups over the course of $22 \mathrm{~h}$ after asphyxia. Body temperature was tightly regulated and did not significantly differ among the experimental groups. The oxygen saturation was gradually restored within $3 \mathrm{~h}$ after asphyxia and was later similar to the values obtained in time controls. Arterial blood pressure was also in the physiological range and was not different among groups. Systolic blood pressure values are plotted, because in preliminary experiments this blood pressure value was more precisely deter-

\section{Histopathology}

In group 1 there was no gross histological alteration discernible in any brain regions studied except for a mild perivascular edema. Accordingly, neuronal injury was minimal (fig. 5). In group 2, asphyxia elicited statistically mined by the non-invasive blood pressure monitor than the diastolic or the mean arterial pressure when compared to simultaneous invasive blood pressure measurements. Asphyxia resulted in tachycardia during the early reventilation that was later restored; however, throughout the observation period the asphyxiated animals showed a tendency for elevated heart rate compared to time controls. b Venous blood $\mathrm{pH}, \mathrm{pCO}_{2}$, and glucose values during the observation period. ${ }^{*} \mathrm{p}<0.05$ versus respective baselines.

significant small increases in the percentage of 'red' neurons in the superficial layers of most neocortical areas, the CA1 region of the hippocampus, the cerebellum, and the medulla oblongata (fig. 5a). $\mathrm{H}_{2}$ ventilation in group 3 resulted in a modest neuroprotective effect: neuronal dam- 


\begin{tabular}{cccc} 
Score & Description & Minimum & Maximum \\
\hline 0 & Isoelectric & 0 & $<2 \mu \mathrm{V}$ \\
\hline 1 & Low voltage & 0 & $<5 \mu \mathrm{V}$ \\
\hline 2 & Burst suppression & $<5 \mu \mathrm{V}$ & $<10 \mu \mathrm{V}$ \\
\hline 3 & Discontinuous 1 & $<5 \mu \mathrm{V}$ & $10-25 \mu \mathrm{V}$ \\
\hline 4 & Discontinuous 2 & $<5 \mu \mathrm{V}$ & $>25 \mu \mathrm{V}$ \\
\hline 5 & Continuous & $>5 \mu \mathrm{V}$ & $>25 \mu \mathrm{V}$ \\
\hline
\end{tabular}

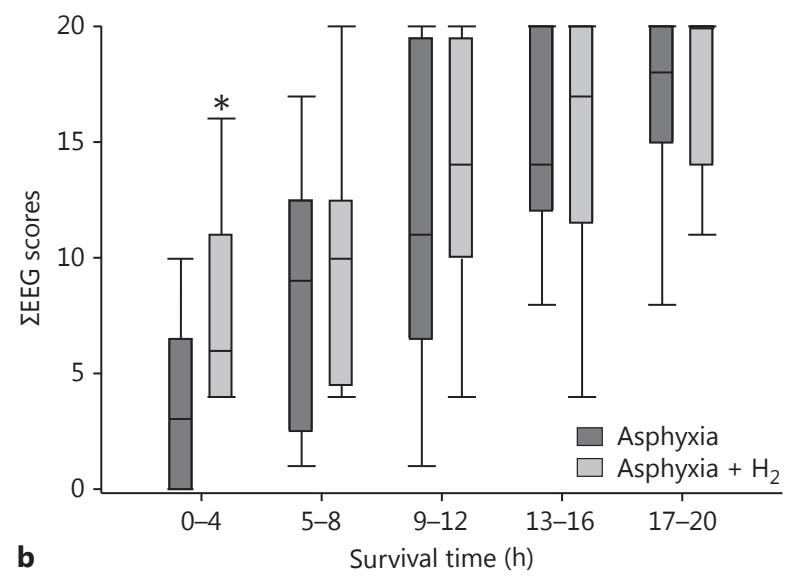

Fig. 3. aEEG scores in groups 2 and 3 over the course of $20 \mathrm{~h}$ after asphyxia. a The aEEG background pattern was evaluated with a scoring system based on Hellstrom-Westas and Rosen [25]. The aEEG score in every animal of the time control group was 5 throughout the observation period (not illustrated). $\mathbf{b}$ aEEG scores determined each hour of survival were summated over 4 -hour pe-

riods. The presented box plots show the median value (thick line), the 25-75th percentile (box), and the 10-90th percentile (error bars). The low voltage activity on the aEEG in the early reventilation gradually recovered over the observed period with large interindividual variability. The recovery was significantly faster during the $\mathrm{H}_{2}$ ventilation in group 3 as compared with group $2{ }^{*} \mathrm{p}<0.05$.

Table 1. Arterial blood $\mathrm{pH}, \mathrm{pCO}_{2}$ and $\mathrm{pO}_{2}$ values during graded hypercapnia

\begin{tabular}{|c|c|c|c|c|c|c|c|c|c|}
\hline & \multicolumn{3}{|l|}{ Baseline } & \multicolumn{3}{|l|}{$5 \% \mathrm{CO}_{2}$} & \multicolumn{3}{|l|}{$10 \% \mathrm{CO}_{2}$} \\
\hline & $\mathrm{pH}$ & $\mathrm{pCO}_{2}$ & $\mathrm{pO}_{2}$ & $\mathrm{pH}$ & $\mathrm{pCO}_{2}$ & $\mathrm{pO}_{2}$ & $\mathrm{pH}$ & $\mathrm{pCO}_{2}$ & $\mathrm{pO}_{2}$ \\
\hline Group 1 & $7.43 \pm 0.03$ & $35 \pm 4$ & $91 \pm 5$ & $7.32 \pm 0.02$ & $43 \pm 3$ & $96 \pm 4$ & $7.19 \pm 0.02$ & $60 \pm 3$ & $99 \pm 8$ \\
\hline Group 2 & $7.42 \pm 0.03$ & $36 \pm 4$ & $77 \pm 5$ & $7.30 \pm 0.01$ & $41 \pm 4$ & $85 \pm 9$ & $7.17 \pm 0.02$ & $64 \pm 3$ & $87 \pm 7$ \\
\hline Group 3 & $7.38 \pm 0.04$ & $40 \pm 4$ & $79 \pm 4$ & $7.30 \pm 0.03$ & $48 \pm 4$ & $83 \pm 5$ & $7.19 \pm 0.02$ & $69 \pm 2$ & $89 \pm 6$ \\
\hline
\end{tabular}

age was significantly smaller in the frontal cortex (versus group 2), and there was no significant difference between groups 1 and 3 in the CA1 region, the cerebellum, and the medulla oblongata (fig. 5).

\section{Discussion}

The first major novel finding of the present study is that severe neurovascular dysfunction is present as late as 1 day after asphyxia in the cerebrocortical microcirculation of newborn piglets. These findings significantly add to and clarify our knowledge on the contribution of altered cerebrovascular regulation to the pathophysiology of HIE. Two early studies reported only decreased CR to hypercapnia and hypotension 1 day after cerebral isch- emia in newborn piglets $[4,15]$. However, the interpretation of these data has been difficult. In those studies, 20 min of no-flow global cerebral ischemia was induced in unanesthetized piglets. Furthermore, hemodynamics, tissue oxygenation and body temperature were not monitored and therefore potential derangements in these parameters could contribute to the observed attenuation of CR. In contrast, in more recent studies, the attenuated CR to numerous stimuli (hypercapnia, NMDA, aprikalim and iloprost) spontaneously recovered $2-4 \mathrm{~h}$ after $10 \mathrm{~min}$ global cerebral ischemia induced in anesthetized animals $[5,6]$. The question whether the attenuation of CR lasts only $1-2 \mathrm{~h}$ or persists as long as $24 \mathrm{~h}$ depending on the severity of the H/I stress (10 vs. $20 \mathrm{~min}$ ) or on the presence of anesthesia, remained unresolved. 
Fig. 4. CR determined to various stimuli in the three experimental groups $24 \mathrm{~h}$ after asphyxia. Baseline pial arteriolar diameters were not significantly different among the experimental groups, for groups 1-3 the values were $88 \pm 11,99 \pm 5$, and $89 \pm 4 \mu \mathrm{m}$, respectively. $\mathrm{PAD}=$ Pial arteriolar dilation. a Graded hypercapnia elicited concentration-dependent vasodilation that was severely attenuated in the animals subjected to asphyxia. $\mathrm{H}_{2}$ ventilation, however, preserved hypercapnia-induced vasodilation. $\mathbf{b}$ NMDA elicited dose-dependent vasodilation that was virtually abolished after asphyxia. NMDA-induced vasodilation was also significantly attenuated in the $\mathrm{H}_{2}$-ventilated group; however, the response was significantly larger compared to the animals reventilated with only air. c NE elicited pial arteriolar constriction that was not significantly altered by asphyxia. Notably, NE-induced vasoconstriction was significantly smaller in the $\mathrm{H}_{2}$-ventilated group. d SNP could dilate pial arterioles in all three experimental groups; although there was a tendency for smaller responses in the asphyxiated animals, these differences were not statistically significant. $\mathrm{p}<0.05:{ }^{*}$ versus time controls (group $1),{ }^{\dagger}$ versus asphyxia (group 2 ).

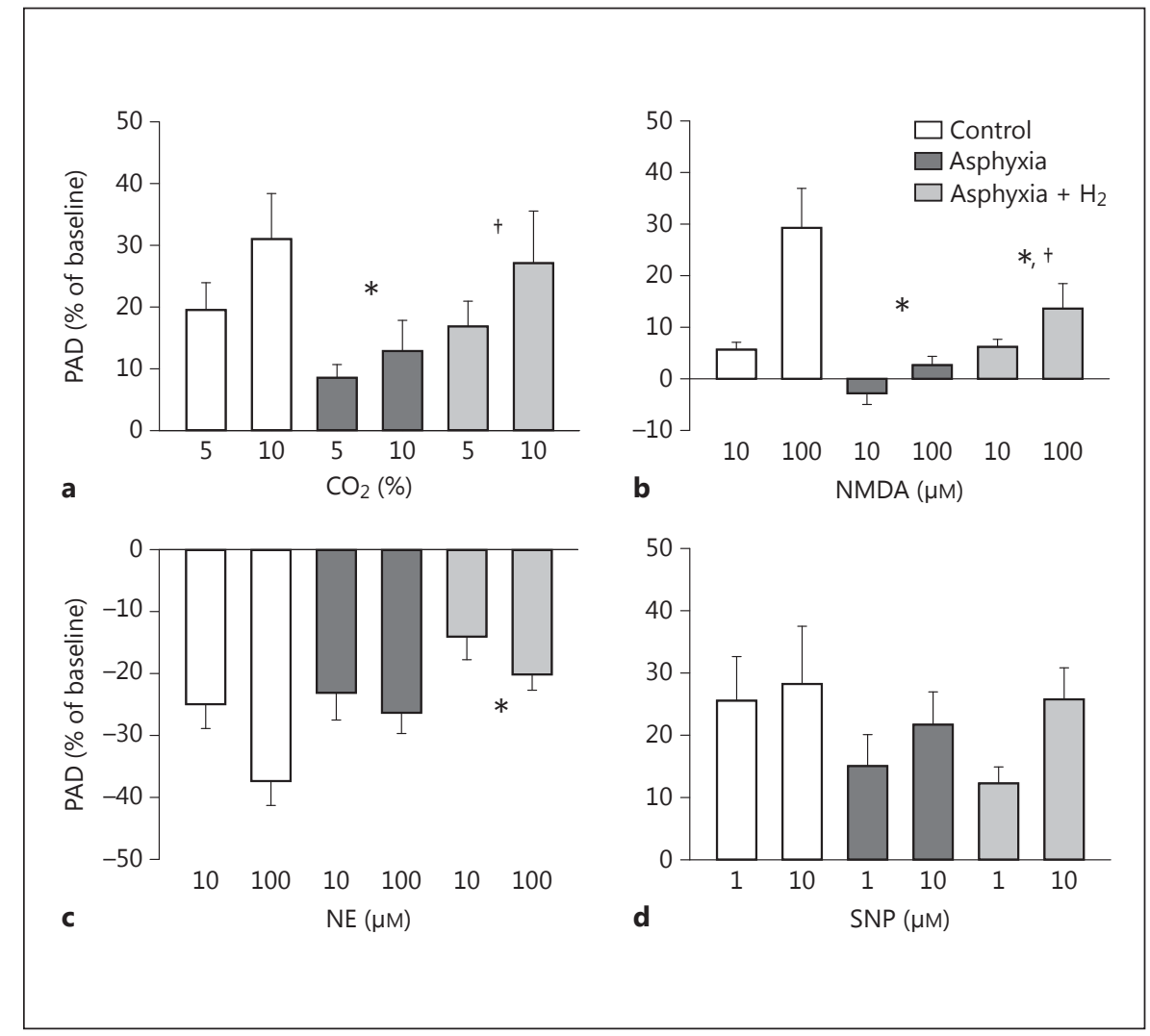

Our present findings strongly suggest that after an initial recovery there is a second bout of neurovascular injury persisting 1 day after a H/I stress. Although we possess no direct evidence that the initial recovery of CR in the present study was similar to that determined in previous studies [5], this can be safely assumed since in the present study we used a milder H/I insult: 8 min asphyxia. Not only the hypoxic period was $20 \%$ reduced, but in this model cortical blood flow is not abruptly stopped but gradually decreases in $4-5$ min to $\sim 20 \%$ of baseline [16]. Indeed, the recovery of the aEEG and the histopathology results also confirm this notion.

In contrast to the yet minor structural brain damage, huge differences in CR between time controls and asphyxiated piglets were observed to hypercapnia and NMDA, and these differences could not be attributed to alterations in hemodynamics, blood chemistry or body temperature. Before the implantation of the closed cranial window for $\mathrm{CR}$ measurements, anesthesia was switched to a-chloralose in order to make the results comparable to previous studies. Indeed, the magnitude of arteriolar dilation in response to these stimuli was virtually identical to those determined in previous experi- ments $[12,14]$. Hypercapnia-induced vasodilation in the piglet is critically dependent on the function of intact microvascular endothelium [14, 17]. However, NMDA-induced vasodilation is a neuronal-vascular process independent of microvascular endothelial function [14, 18]. Thus, the delayed impairment of CR was found to involve both the neuronal and the microvascular elements of the neurovascular unit vulnerable to $\mathrm{H} / \mathrm{I}$ stress.

The second major novel finding of the present study is that $\mathrm{H}_{2}$ in the early $(4 \mathrm{~h})$ reventilation period following asphyxia has a remarkable delayed protective effect on neurovascular unit function in the neonate. $\mathrm{H}_{2}$ has been shown previously not to directly affect CR [12]. In addition, in the present study, $\mathrm{H}_{2}$ ventilation was stopped $20 \mathrm{~h}$ before the CR measurements excluding the possibility of the direct involvement of $\mathrm{H}_{2}$ on the observed preservation to $\mathrm{CR}$. $\mathrm{H}_{2}$ was originally described as a selective hydroxyl radical scavenger and was found neuroprotective in an adult rat stroke model [11]. However, hydroxyl radicals can be even more important determinants of oxidative stress in the neonate than in the adult [19]. In neonatal rats, $\mathrm{H}_{2}$ was found neuroprotective in the RiceVanucci H/I model [20], and it protected against the de- 


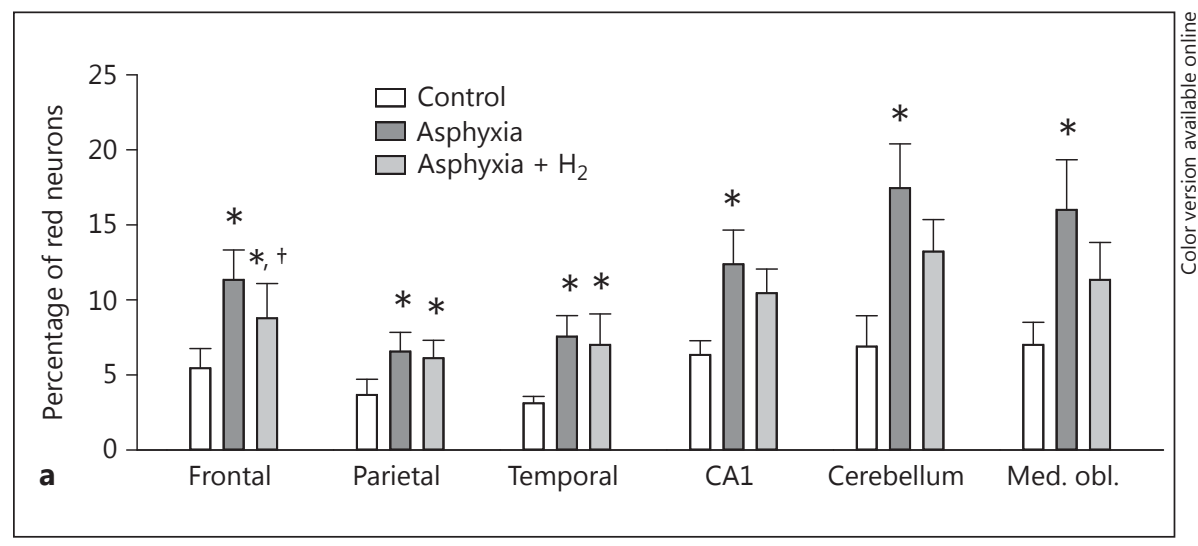

Fig. 5. a Histopathological evaluation of different brain regions in the three experimental groups 1 day after asphyxia. In time controls, damaged neurons were rare. Asphyxia elicited a modest but statistically significant increase in the frequency of damaged red neurons in most areas of the cerebral cortex, the CA1 region of the hippocampus, the cerebellum, and the medulla oblongata. There was no significantly elevated neuronal damage in the caudate nucleus, the occipital cortex, and other assessed areas of the hippocampus (CA2, $\mathrm{CA} 3$, and stratum granulare); these data are not plotted. In most regions (frontal cortex, CA1, cerebellum, and medulla oblongata), $\mathrm{H}_{2}$ ventilation yielded a small neuroprotective effect. $\mathrm{p}<0.05$ : ${ }^{*}$ versus time controls (group 1$),{ }^{\dagger}$ versus asphyxia (group 2), statistical power ranged between 0.44 and 0.64 . b Representative photomicrographs of frontal cortex, CA1 region of hippocampus and medulla oblongata. Scale bar: $100 \mu \mathrm{m}$.

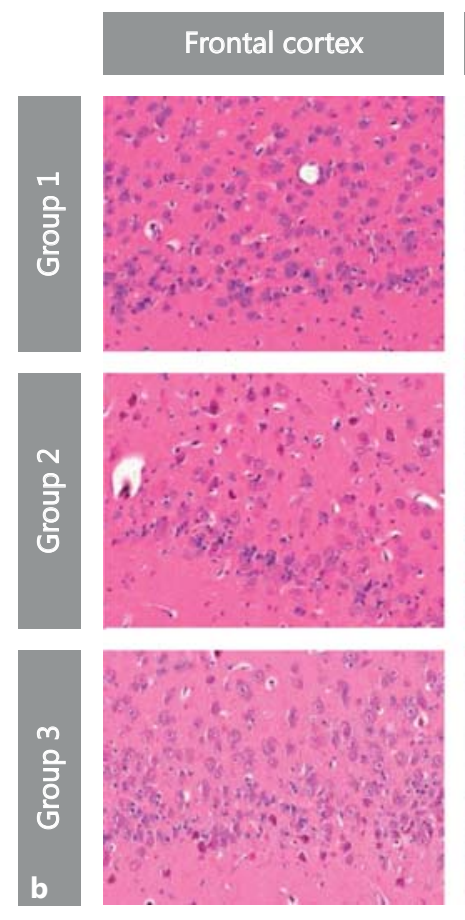

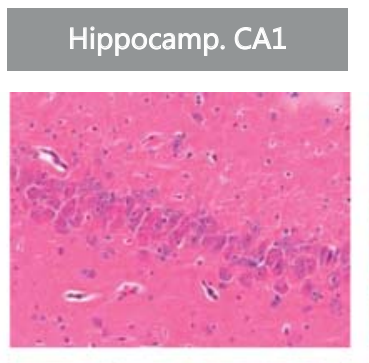
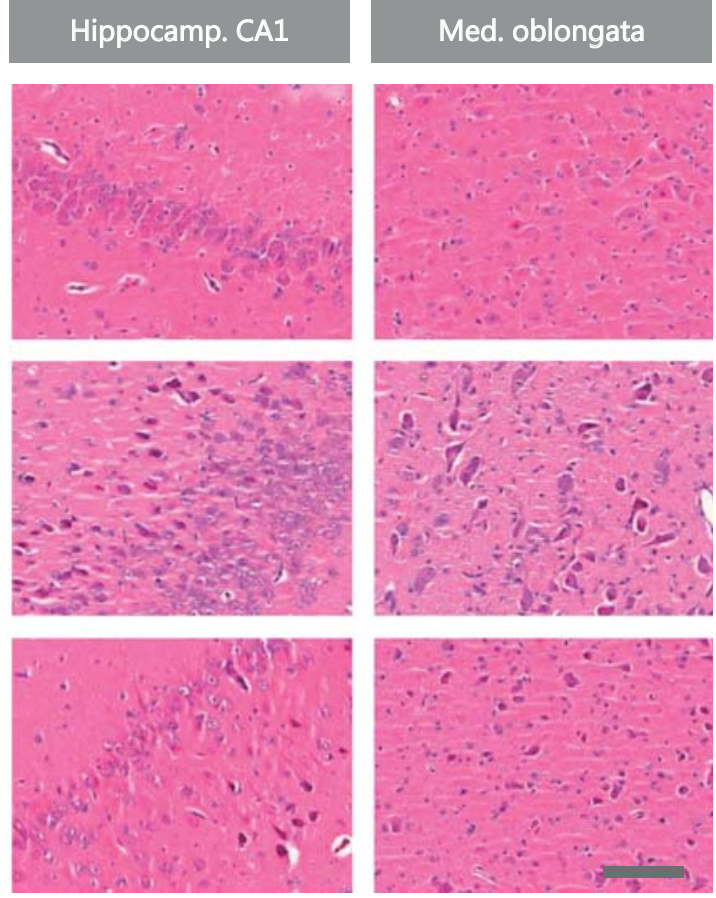

velopment of cognitive impairment, cerebral palsy, and brain atrophy 1 month after germinal matrix hemorrhage [21]. In a large animal model, our previous study first demonstrated this neuroprotective effect along with the protective effect on CR in the early reventilation period [12]. The protective effect of $\mathrm{H}_{2}$ on $\mathrm{CR}$ in this period fully complies with its antioxidant potential, since ROS produced during the reoxygenation after $\mathrm{H} / \mathrm{I}$ stress undoubtedly play a pivotal role in the early impairment of CR to NMDA [10]. Hypercapnia-induced vasodilation is also attenuated by ROS through microvascular endothelial injury $[14,17,22]$.

We believe that this $\mathrm{H}_{2}$ administration regimen would be also a clinically plausible therapy for asphyxiated in- fants: starting with the resuscitation and ending in a cooling center where therapeutic hypothermia can be introduced ( $\leq 6 \mathrm{~h}$ postnatally) [23]. The efficacy of early $\mathrm{H}_{2}$ administration to fully (hypercapnia) or partially (NMDA) preserve neurovascular function 1 day after the insult underscores the possibility that ROS-inflicted damages to the neurovascular unit in the early reventilation period trigger the development of delayed neurovascular dysfunction perhaps similar to the delayed energy failure observed also in this period. An interesting finding of the present study was that the H/I-insensitive NE-induced vasoconstriction [15] was significantly less in the $\mathrm{H}_{2^{-}}$ treated animals. This slight difference may have little biological significance, but the smaller steady-state pial arte- 
riolar constriction in this group could represent a more agile counterregulatory mechanism to limit the repeated development of oligemia/ischemia in the cerebral cortex after $\mathrm{H} / \mathrm{I}$ stress.

In summary, even a relatively mild $\mathrm{H} / \mathrm{I}$ injury triggers severe delayed dysfunction of the neurovascular unit affecting both cerebrovascular and neurovascular regulatory mechanisms. This delayed functional impairment in cerebrovascular regulation thus likely develops also after clinically relevant $\mathrm{H} / \mathrm{I}$ stress levels and disrupts the relationship between tissue metabolism and cortical blood flow leading to further neuronal damage during the development of $\mathrm{HIE}$. Resuscitation with a $\mathrm{H}_{2}$-air mixture in the early reventilation period can alleviate delayed neuro- vascular damage and may offer inexpensive and valuable supplementary neuroprotection bridging the gap between resuscitation and the induction of whole-body hypothermia.

\section{Acknowledgements}

This study was supported by grants from the National Scientific Research Fund of Hungary (OTKA, K81266, K100851) and from the EU (HURO/0901/137/2.2.2). O. Oláh was supported through the TÁMOP-4.2.2/B-10/1-2010-0012 grant. F. Domoki was supported by the János Bolyai Research Scholarship of the Hungarian Academy of Sciences.

\section{References}

1 Azzopardi DV, Strohm B, Edwards AD, Dyet L, Halliday HL, Juszczak E, Kapellou O, Levene $\mathrm{M}$, Marlow N, Porter E, Thoresen M, Whitelaw A, Brocklehurst P: Moderate hypothermia to treat perinatal asphyxial encephalopathy. N Engl J Med 2009;361:1349-1358.

2 Christensen RD, Sheffield MJ, Lambert DK, Baer VL: Effect of therapeutic hypothermia in neonates with hypoxic-ischemic encephalopathy on platelet function. Neonatology 2012; 101:91-94.

3 Xing C, Hayakawa K, Lok J, Arai K, Lo EH: Injury and repair in the neurovascular unit. Neurol Res 2012;34:325-330.

4 Leffler CW, Busija DW, Armstead WM, Mirro R, Beasley DG: Ischemia alters cerebral vascular responses to hypercapnia and acetylcholine in piglets. Pediatr Res 1989;25:180183.

5 Busija DW, Meng W, Bari F, McGough PS, Errico RA, Tobin JR, Louis TM: Effects of ischemia on cerebrovascular responses to $\mathrm{N}$ methyl-D-aspartate in piglets. Am J Physiol 1996;270:H1225-H1230.

6 Bari F, Louis TM, Meng W, Busija DW: Global ischemia impairs ATP-sensitive $\mathrm{K}^{+}$channel function in cerebral arterioles in piglets. Stroke 1996;27:1874-1880.

7 Domoki F, Perciaccante JV, Puskar M, Bari F, Busija DW: Cyclooxygenase-2 inhibitor NS398 preserves neuronal function after hypoxia/ischemia in piglets. Neuroreport 2001; 12:4065-4068.

8 Lorek A, Takei Y, Cady EB, Wyatt JS, Penrice J, Edwards AD, Peebles D, Wylezinska M, Owen-Reece H, Kirkbride V, et al: Delayed ('secondary') cerebral energy failure after acute hypoxia-ischemia in the newborn piglet: continuous 48 -hour studies by phosphorus magnetic resonance spectroscopy. Pediatr Res 1994;36:699-706.
9 Fike CD, Kaplowitz M, Zhang Y, Dantuma M, Madden JA: Effect of a phosphodiesterase-5 inhibitor on pulmonary and cerebral arteries of newborn piglets with chronic hypoxia-induced pulmonary hypertension. Neonatology 2012;101:28-39.

10 Bari F, Errico RA, Louis TM, Busija DW: Differential effects of short-term hypoxia and hypercapnia on N-methyl-D-aspartate-induced cerebral vasodilatation in piglets. Stroke 1996; 27:1634-1640.

11 Ohsawa I, Ishikawa M, Takahashi K, Watanabe M, Nishimaki K, Yamagata K, Katsura K, Katayama Y, Asoh S, Ohta S: Hydrogen acts as a therapeutic antioxidant by selectively reducing cytotoxic oxygen radicals. Nat Med 2007;13:688-694.

12 Domoki F, Olah O, Zimmermann A, Nemeth I, Toth-Szuki V, Hugyecz M, Temesvari P, Bari F: Hydrogen is neuroprotective and preserves cerebrovascular reactivity in asphyxiated newborn pigs. Pediatr Res 2010;68:387-392.

13 Maynard D, Prior PF, Scott DF: Device for continuous monitoring of cerebral activity in resuscitated patients. Br Med J 1969;4:545546.

14 Domoki F, Perciaccante JV, Shimizu K, Puskar M, Busija DW, Bari F: N-methyl-D-aspartate-induced vasodilation is mediated by endothelium-independent nitric oxide release in piglets. Am J Physiol Heart Circ Physiol 2002;282:H1404-H1409.

15 Leffler CW, Busija DW, Beasley DG, Armstead WM, Mirro R: Postischemic cerebral microvascular responses to norepinephrine and hypotension in newborn pigs. Stroke 1989;20:541-546.

16 Domoki F, Zimmermann A, Cserni G, Bori R, Temesvari P, Bari F: Reventilation with room air or $100 \%$ oxygen after asphyxia differentially affects cerebral neuropathology in newborn pigs. Acta Paediatr 2006;95:1109-1115.
17 Leffler CW, Mirro R, Shanklin DR, Armstead WM, Shibata M: Light/dye microvascular injury selectively eliminates hypercapnia-induced pial arteriolar dilation in newborn pigs. Am J Physiol Heart Circ Physiol 1994; 266:H623-H630.

18 Busija DW, Bari F, Domoki F, Louis T: Mechanisms involved in the cerebrovascular dilator effects of N-methyl-D-aspartate in cerebral cortex. Brain Res Rev 2007;56:89-100.

19 Lafemina MJ, Sheldon RA, Ferriero DM: Acute hypoxia-ischemia results in hydrogen peroxide accumulation in neonatal but not adult mouse brain. Pediatr Res 2006;59:680683.

20 Cai J, Kang Z, Liu K, Liu W, Li R, Zhang JH, Luo X, Sun X: Neuroprotective effects of hydrogen saline in neonatal hypoxia-ischemia rat model. Brain Res 2009;1256:129-137.

21 Lekic T, Manaenko A, Rolland W, Fathali N, Peterson M, Tang J, Zhang JH: Protective effect of hydrogen gas therapy after germinal matrix hemorrhage in neonatal rats. Acta Neurochir Suppl 2011;111:237-241.

22 Leffler CW, Busija DW, Armstead WM, Shanklin DR, Mirro R, Thelin O: Activated oxygen and arachidonate effects on newborn cerebral arterioles. Am J Physiol 1990; 259:H1230-H1238.

23 Roka A, Azzopardi D: Therapeutic hypothermia for neonatal hypoxic ischaemic encephalopathy. Early Hum Dev 2010;86:361-367.

24 Dannevig I, Solevag AL, Wyckoff M, Saugstad OD, Nakstad B: Delayed onset of cardiac compressions in cardiopulmonary resuscitation of newborn pigs with asphyctic cardiac arrest. Neonatology 2011;99:153-162.

25 Hellstrom-Westas L, Rosen I: Continuous brain-function monitoring: state of the art in clinical practice. Semin Fetal Neonatal Med 2006;11:503-511. 